\title{
Gender difference in response predictors after 1 -year exenatide therapy twice daily in type 2 diabetic patients: a real world experience
}

This article was published in the following Dove Press journal:

Diabetes, Metabolic Syndrome and Obesity:Targets and Therapy

5 April 2013

Number of times this article has been viewed

\author{
Roberto Anichini' \\ Sabrina Cosimi \\ Alberto Di Carlo ${ }^{3}$ \\ Paola Orsini ${ }^{4}$ \\ Alessandra De Bellis' \\ Giuseppe Seghieri' \\ Flavia Franconi ${ }^{5}$ \\ Fabio Baccetti ${ }^{6}$ \\ 'Diabetes Unit, Spedali Riuniti, \\ Pistoia, Italy; ${ }^{2}$ Diabetes Unit, Hospital \\ of Versilia, Camaiore (LU), Italy; \\ ${ }^{3}$ Diabetes Unit, Hospital of Lucca, \\ Italy; ${ }^{4}$ Diabetes Unit, Hospital of \\ Livorno, Italy; ${ }^{5}$ Department of \\ Biochemical Sciences, University of \\ Sassari, Italy; ${ }^{6}$ Diabetes Unit, Hospital \\ of Massa, Italy
}

Purpose: To investigate whether gender affects therapeutic response by exenatide twice a day (BID) in type 2 diabetes by using a database concerning patients monitored by five outpatient clinics in Tuscany, Italy.

Patients and methods: We considered a cohort of 315 (154 male/161 female) patients experiencing therapeutic failure while on oral therapy (metformin, or combination therapy metformin + sulphonylureas), who were given exenatide (10 $\mu \mathrm{g} / \mathrm{BID})$ and who fully completed 4 months, 8 months, and 12 months of follow-ups.

Results: Among patients stratified by gender and well matched for age, body mass index, and hemoglobin $\mathrm{A}_{1 \mathrm{c}}\left(\mathrm{HbA}_{1 \mathrm{c}}\right)$, it was found that the length of disease was longer in females than in males ( $12 \pm 8$ years versus $10 \pm 7$ years; $P=0.037$ ), and the ratio of patients on metformin to those on combination therapy was higher in men $(P=0.018)$. Target glycemic response (1-year $\left.\mathrm{HbA}_{1 \mathrm{c}} \leq 7 \%\right)$ was achieved in a significantly higher proportion of males than females $(38 \%$ versus $\left.27 \% ; \chi^{2}=4.66 ; P=0.03\right)$. Target weight loss expressed as 1 -year weight percent fall from baseline $\geq 75$ th percentile $(8.5 \%)$ was significantly higher in females at 8 and 12 months ( $P<0.05$; for both). One-year glycemic target response was inversely related to baseline $\mathrm{HbA}_{1 \mathrm{c}}$ levels and diabetes duration among males, while metformin therapy (compared to oral combination therapy) was a significant predictor of better glycemic targets among females. Homeostasis model assessment-B, measured in 117 patients, predicted hypoglycemic response only in women $(P=0.009)$. Target 1-year weight loss was predicted by longer diabetes duration among males and by lower baseline $\mathrm{HbA}_{1 \mathrm{c}}$ among females. Finally, no significant difference between genders was noted as to gastrointestinal side effects after exenatide therapy.

Conclusion: According to this "real world" experience, predictors of glycemic control and body weight loss after 12 months of exenatide BID therapy are different between genders in type 2 diabetes.

Keywords: GLP-1 agonist therapy, exenatide BID, type 2 diabetes, real world setting

\section{Introduction}

Maintenance of strict glycemic control prevents or delays the risk of microangiopathy and, to a lesser degree, of macroangiopathy in patients with type 2 diabetes. ${ }^{1,2}$ The primary aim of therapy in diabetes is, therefore, to achieve target glycemic control, with a rate of hypoglycemic episodes or adverse events as reduced as possible., ${ }^{3,4}$

Besides diet and physical exercise, both metformin and $\beta$-cell secretagogues can be administered by an "add on" modality. ${ }^{5}$ In case of therapeutic failure, a further opportunity is given by glucagon-like peptide-1 (GLP-1) receptor agonists, such as exenatide. ${ }^{6-8}$ GLP-1 receptor agonists exert their hypoglycemic effect through stimulation of glucose-dependent insulin release coupled with a reduction of glucagon
Correspondence: Giuseppe Seghier Department of Internal Medicine, Spedali Riuniti,Viale Matteotti 9/D 5 I 100 Pistoia, Italy

Tel +393386941642

Fax +390573352005

Email gseghier@tin.it 
release from pancreatic $\alpha$-cells, cumulatively leading to protective effects on $\beta$-cell mass. ${ }^{9,10}$ In addition, GLP-1 receptor agonists elicit satiety sensation and slow gastric empting. ${ }^{11-13}$

In conclusion, GLP-1 receptor agonists such as exenatide obtain their therapeutic effects by reducing the risk of hypoglycemic events and, at the same time, by leading to significant weight loss, especially in obese patients. ${ }^{14-18}$

Many randomized controlled trials have, over the past years, confirmed the efficacy of exenatide either in monotherapy, or in an "add on" therapeutic strategy, 5,19 while only few studies have been published about exenatide therapy in real world clinical settings $;^{20,21}$ scarce data exist about gender differences concerning the use of exenatide in routine practice.

An additional interest also lies in the observation that in normal weight individuals, the release of endogenous GLP-1 elicited by fiber-rich nutrients is sexually dimorphic, being selectively potentiated in women. ${ }^{22}$

Exenatide, which has been available in Italy since February 2008, is prescribed in our country as an adjunctive therapy to metformin, sulphonylureas, their combination, or thiazolidinediones and until 2010 its use, as well as its reimbursement, have been approved, only after recording patients into a specific web-assisted-computerized database. We have, therefore, utilized this database to investigate whether and possibly how the therapeutic response by exenatide in type 2 diabetes is different between genders.

\section{Materials and methods}

\section{Patients}

This multicentric, observational, retrospective study involved type 2 diabetic patients enrolled in five diabetes outpatient clinics in Tuscany, Italy (Livorno, Lucca, Massa, Pistoia, and Versilia) between February 2008 and August 2010. Patients were recruited at each center if they had experienced therapeutic failure despite maximum-tolerated oral treatment (metformin, or combination metformin + sulphonylureas), or had adverse events after conventional oral therapy. There was also a very exiguous number of patients who were in therapy with sulphonylureas $(n=8)$ or thiazolidinediones $(n=3)$ only and, consequently, for the purpose of this study, we considered only two therapeutic groups (those on metformin/thiazolidinediones and those on combination therapy/sulphonylureas).

All patients began treatment with exenatide $5 \mu \mathrm{g}$ twice daily (BID), injected subcutaneously 30-40 minutes before principal meals, for 4 weeks; if treatment was well tolerated, the dosing was increased to $10 \mu \mathrm{g}$ twice daily. Background therapy was generally kept at prestudy dosage unless patients had experienced hypoglycemic episodes. According to scheduled follow-ups, each patient was reevaluated after 4 months, 8 months, and 12 months. At each visit, body weight, waist circumference, fasting plasma glucose, hemoglobin $\mathrm{A}_{1 \mathrm{c}}\left(\mathrm{HbA}_{1 \mathrm{c}}\right)$ and adverse events were recorded.

In a subset of 117 (61 male/56 female) patients, fasting plasma C-peptide was measured and homeostasis model assessment-B (HOMA-B) was calculated as: ${ }^{23}$

$$
\begin{gathered}
20 \times \text { plasma C-peptide }(\mathrm{ng} / \mathrm{mL}) \\
\text { /fasting plasma glucose }(\mathrm{mmol} / \mathrm{L})-3.5 \text {. }
\end{gathered}
$$

With these premises, the purpose of this study was to retrospectively identify predictors of target glycemic response $\left(\mathrm{HbA}_{1 \mathrm{c}} \leq 7 \%\right)$, and of weight loss in males as compared to females, adding further information about the rates of drop-outs and of side effects in our population.

Plasma glucose, $\mathrm{HbA}_{1 \mathrm{c}}$, and plasma C-peptide were measured in all centers by means of standardized methods, with periodical quality control checks. In each center, use of information contained in the database was approved by the local ethics committee.

\section{Statistics}

Differences between means were evaluated according to both parametric (Student's $t$-test) and nonparametric (Wilcoxon rank-sum test) methods, when appropriate. The Chi-square test was used to compare frequencies. Predictors of main outcomes at 1 year $\left(\mathrm{HbA}_{1 \mathrm{c}}\right.$ or body weight loss at target) were identified in both genders, calculating the odds ratio from multiple logistic models including sets of continuous or categorical independent variables. For continuously distributed independent variables, odds ratios measured variations in risk according to either the increase or decrease is proportional to the consensual change of the unity of measure of the independent variable. Data are expressed as means \pm standard deviation, or as median values (interquartile range), and a $P$-value $\leq 0.05$ was considered statistically significant.

All analyses were performed with SAS software, version 8.2 for Windows (SAS Institute, Cary, NC, USA).

\section{Results}

The group of patients under study was composed of 154 males and 161 females, who were well matched for age, baseline body mass index (BMI), and $\mathrm{HbA}_{1 \mathrm{c}}$ (Table 1). Among females, menopause was present in 143 (89\%) individuals. 
Table I Main characteristics of male and female patients at baseline and at scheduled follow-ups

\begin{tabular}{|c|c|c|c|c|c|c|c|c|}
\hline & \multicolumn{4}{|l|}{ Males $(n=154)$} & \multicolumn{4}{|c|}{ Females $(n=161)$} \\
\hline & Baseline & 4 months & 8 months & 12 months & Baseline & 4 months & 8 months & 12 months \\
\hline Age (years) & $59.4 \pm 8.1$ & - & - & - & $59.7 \pm 8.9$ & - & - & - \\
\hline $\begin{array}{l}\text { Therapy M/SU + } \\
\text { M/SU/other (\%) }\end{array}$ & $53.9 / 43.5 / 1.9 / 0.6$ & - & - & - & $4 I .2 / 55.6 / 3.1 / 0 *$ & - & - & - \\
\hline Diabetes duration (years) & $10.4 \pm 7.4$ & - & - & - & $12.2 \pm 7.8^{*}$ & - & - & - \\
\hline Weight (kg) & $102.3 \pm 17.5$ & $98.1 \pm 17$ & $97.5 \pm 16.2$ & $97.3 \pm 16.3$ & $89.4 \pm 16.7$ & $85.2 \pm 16.4$ & $83.6 \pm 15.9$ & $83.7 \pm 16.5$ \\
\hline BMI $\left(\mathrm{kg} / \mathrm{m}^{2}\right)$ & $33.3 \pm 5.4$ & $31.9 \pm 5.2$ & $31.7 \pm 4.9$ & $31.6 \pm 5$ & $34.4 \pm 6.3$ & $32.7 \pm 6.2$ & $32.3 \pm 6.2$ & $32.3 \pm 6.5$ \\
\hline $\begin{array}{l}\text { Fasting plasma glucose } \\
(\mathrm{mmol} / \mathrm{L})\end{array}$ & $10.3 \pm 2.8$ & $8.5 \pm 2.6$ & $8.5 \pm 2.2$ & $8.4 \pm 2.4$ & $9.7 \pm 2.4^{*}$ & $8.6 \pm 2.5$ & $8.6 \pm 2.5$ & $8.6 \pm 2.4$ \\
\hline $\mathrm{HbA}_{\mathrm{Ic}}(\%)$ & $8.8 \pm 1.2$ & $7.5 \pm 1.1$ & $7.6 \pm 1.3$ & $7.5 \pm 1.1$ & $8.7 \pm 1.0$ & $7.7 \pm 1.1$ & $7.7 \pm 1.2$ & $7.6 \pm 1.1$ \\
\hline HOMA-B** & $2.97(2.20)$ & $4.62(4.52)$ & $3.54(5.16)$ & $4.05(6.07)$ & $2.84(2.33)$ & $3.29(4.24)$ & $3.89(3.60)$ & $3.13(2.60)$ \\
\hline
\end{tabular}

Notes: $* P<0.05$ versus males; **obtained in 60 males and in 55 females, expressed as median value (interquartile range).

Abbreviations: $n$, number; $M$, metformin; $S U$, metformin + sulphonylureas; BMI, body mass index; HbA $A_{1 c}$, hemoglobin $A_{1 c}$; HOMA-B, homeostasis model assessment-B.

Baseline mean fasting plasma glucose was higher among males, while females were characterized by a longer duration of diabetes as well as by a higher prevalence of patients treated with combination therapy (sulphonylureas + metformin) (Table 1).

No differences in mean values of mean plasma glucose, $\mathrm{HbA}_{1 \mathrm{c}}$, or BMI at baseline, at 4 months, 8 months, and 12 months were observed between genders (Table 1 and Figure 1). The percentage of patients who achieved the target glycemic value $\left(\mathrm{HbA}_{1 \mathrm{c}} \leq 7 \%\right)$ was significantly higher among males than females after 4 months ( $41 \%$ versus $28 \%$; $\left.\chi^{2}=6.21 ; P=0.01\right)$, as well as after 12 months $(38 \%$ versus $27 \% ; \chi^{2}=4.66 ; P=0.03$; Figure $\left.1 \mathrm{~B}\right)$.

BMI was, on average, greater (even if not significantly) in females than in males throughout the whole period (Table 1, and Figure 1A). Target weight loss, arbitrarily expressed as 1-year percent loss $\geq 75$ th percentile in the whole population $(8.5 \%)$, was more often achieved among females at 8 months $\left(28 \%\right.$ versus $\left.15 \% ; \chi^{2}=8.04 ; P=0.004\right)$ and 12 months $\left(33 \%\right.$ versus $\left.17 \% ; \chi^{2}=10.98 ; P=0.0009\right)$ (Figure 1B). After substituting body weight with BMI, the results did not change (data not shown).
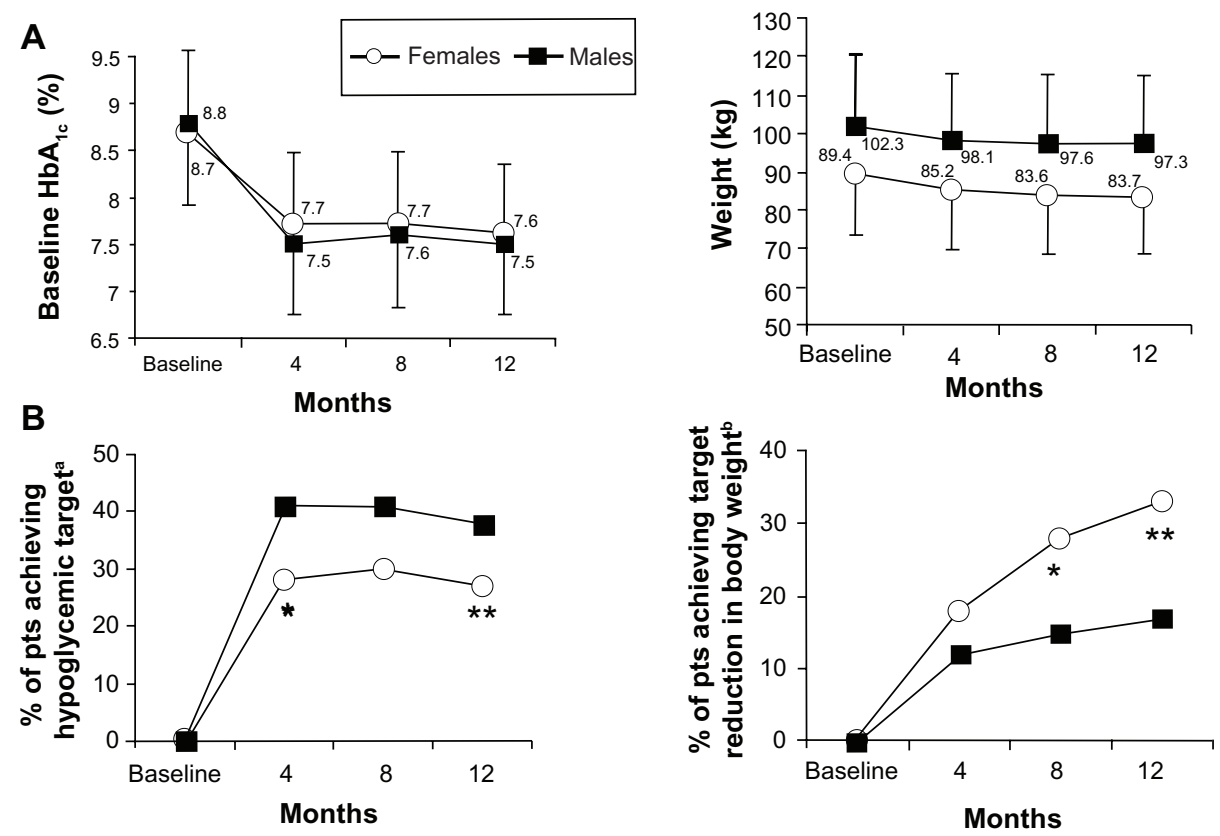

Figure I Mean values of $\mathrm{HbA}_{\mathrm{Ic}}$ and body weight at baseline, and at 4 months, 8 months, and $\mathrm{I} 2$ months in males and females. Mean values of $\mathrm{HbA}$ (left) and body weight (right) at baseline, and at 4 months, 8 months, and 12 months in males and females (A). The percentage of both male and female patients who achieved target glycemic control $\left(\mathrm{HbA}_{\mathrm{lc}} \leq 7 \%\right)$ (left) and body weight reduction targeted at $\geq 8.5 \%$ (75th percentile of I-year percent loss from the baseline weight value) over the observation

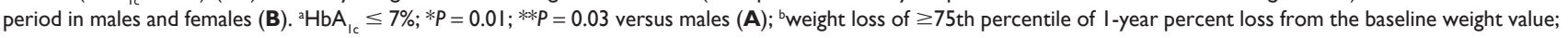
$* P=0.004 ; * * P=0.0009$ versus males $(\mathbf{B})$.

Abbreviation: $\mathrm{HbA}_{1 \mathrm{c}}$, hemoglobin $\mathrm{A}_{\mathrm{lc}}$. 
Predictors of target metabolic response at 1 year, $\left(\mathrm{HbA}_{1 \mathrm{c}} \leq 7 \%\right)$, was evaluated by using a multiple logistic model where the dependent variable (y) was the positive target outcome attained (yes $=1$; no $=0$ ), and age, duration of diabetes, baseline $\mathrm{HbA}_{1 \mathrm{c}}$, $\mathrm{BMI}$, and background antidiabetic therapy (metformin/thiazolidinediones or combination therapy/sulphonylureas, respectively categorized as 0 and 1), were independent variables.

Duration of the disease was inversely related with the probability of achieving 1-year target glycemic outcomes, and in the whole population, each increase in 1-year diabetes duration reduced the probability of achieving the glycemic target by about the $6 \%$. Likewise, baseline $\mathrm{HbA}_{1 \mathrm{c}}$ was inversely related with 1-year target glycemic response. Each $1 \%$ increase of $\mathrm{HbA}_{1 \mathrm{c}}$ reduced the probability of achieving the glycemic target at 12 months by about 35\% (Table 2 and Figure 2).

Longer disease duration and higher basal $\mathrm{HbA}_{1 \mathrm{c}}$ levels were significantly negative predictors of target metabolic response in men, while in women negative achievement of the 1-year glycemic target was associated with baseline treatment with sulphonylureas or a combination oral therapy, with baseline therapy with metformin being related to a positive outcome at 1 year (OR: 0.321 [95\% CI: 0.148-0.696]) (Table 2).

Increase in baseline HOMA-B was significantly related to 1 -year positive metabolic response only in females (Table 2).

A longer duration of diabetes was a significant predictor of a target weight loss response in the overall population; also, in this case there was a difference between genders since lower $\mathrm{HbA}_{1 \mathrm{c}}$ levels at baseline was a significant 1 -year response predictor in females, while longer diabetes duration was a significant 1 -year response predictor in males (Table 3).

Table 4 shows the types of side effects and reasons for drop-outs; there was no clear gender difference with regards to the prevalence of the most common gastrointestinal side effects.

\section{Discussion}

In this observational study, exenatide was used at the standard dose as an add-on strategy in diabetic patients experiencing therapeutic failure.

As expected, the duration of diabetes and the baseline $\mathrm{HbA}_{1 \mathrm{c}}$ levels were among the main predictors of therapeutic glycemic response. In fact, a longer duration of diabetes and increasingly elevated $\mathrm{HbA}_{1 \mathrm{c}}$ levels are both significant predictors of $\beta$-cell dysfunction, ${ }^{24-27}$ and are thus responsible for impairing the therapeutic effect of antidiabetic drugs including GLP-1 receptor agonists.

The therapeutic glycemic effect was similar to what has been reported by previous intervention trials, ${ }^{16,18,20}$ and the new data of the present study illustrates the observed gender difference in the attainment of metabolic targets achieved by a significantly higher proportion of males $(38 \%)$ than females $(27 \%)$.

Currently, to the best of our knowledge, there are no reports about the influence of gender on hypoglycemic responses in diabetic patients treated with exenatide, since previously published studies refer to randomized controlled trials, which are often of short duration and they usually compare exenatide with other active drugs. ${ }^{18}$ Furthermore, in many trials, gender distribution was unbalanced with the percentage of males (in most cases) being above $50 \%,{ }^{18}$ suggesting that the final results could have been influenced by gender mismatching. Very recently, a retrospective post hoc meta-analysis of Pencek et $\mathrm{al}^{28}$ regarding 16 studies and 2067 diabetic patients treated with exenatide BID did not reveal any gender difference as to the glycemic outcome. This may be due to the fact that the main characteristics of patients analyzed by Pencek et $\mathrm{al}^{28}$ were quite different from those of our patients with regards to age, matching of sex, background therapy, duration of trial, and race. It is interesting, however,

Table 2 Predictors of the glycemic target $\left(\mathrm{HbA}_{\mathrm{lc}} \leq 7 \%\right)$ in the overall population, as well as in males and females

\begin{tabular}{|c|c|c|c|}
\hline & $\begin{array}{l}\text { Males } \\
\text { OR }(95 \% \mathrm{Cl})\end{array}$ & $\begin{array}{l}\text { Females } \\
\text { OR }(95 \% \mathrm{Cl})\end{array}$ & $\begin{array}{l}\text { Overall } \\
\text { OR }(95 \% \mathrm{Cl})\end{array}$ \\
\hline Diabetes duration & $0.864(0.800-0.932)^{\mathrm{a}}$ & $0.998(0.947-\mid .05 I)$ & $0.942(0.904-0.982)^{a}$ \\
\hline Baseline BMI & I.049 (0.977-I.II26) & $1.003(0.946-1.063)$ & $1.013(0.970-1.057)$ \\
\hline Baseline $\mathrm{HbA}_{\mathrm{lc}}$ & $0.520(0.354-0.764)^{\mathrm{a}}$ & $0.691(0.462-1.033)$ & $0.646(0.498-0.839)^{a}$ \\
\hline Therapy* & $1.458(0.656-3.240)$ & $0.321(0.148-0.696)^{\mathrm{a}}$ & $0.596(0.352-1.007)$ \\
\hline HOMA-B** & $0.799(0.529-1.208)$ & I.668 (I.07I-2.599) & $1.679(0.993-2.838)$ \\
\hline
\end{tabular}

Notes: Results are expressed as OR $(95 \% \mathrm{Cl})$ after a logistics regression model where the dependent variable was target outcome " $y$ " (yes $=1$; no $=0$ ), and age, duration of diabetes, baseline $\mathrm{HbA}_{\mathrm{Ic}}$, background antidiabetic therapy, and baseline BMI were the independent variables. *Therapy was categorized as metformin $=0$; sulphonylureas

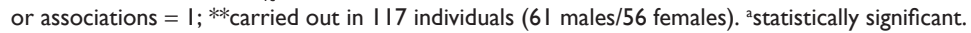

Abbreviations: $\mathrm{HbA}_{\mathrm{Ic}}$, hemoglobin $\mathrm{A}_{\mathrm{Ic}}$; OR, odds ratio; $\mathrm{Cl}$, confidence interval; $\mathrm{BMI}$, body mass index; HOMA-B, homeostasis model assessment-B. 

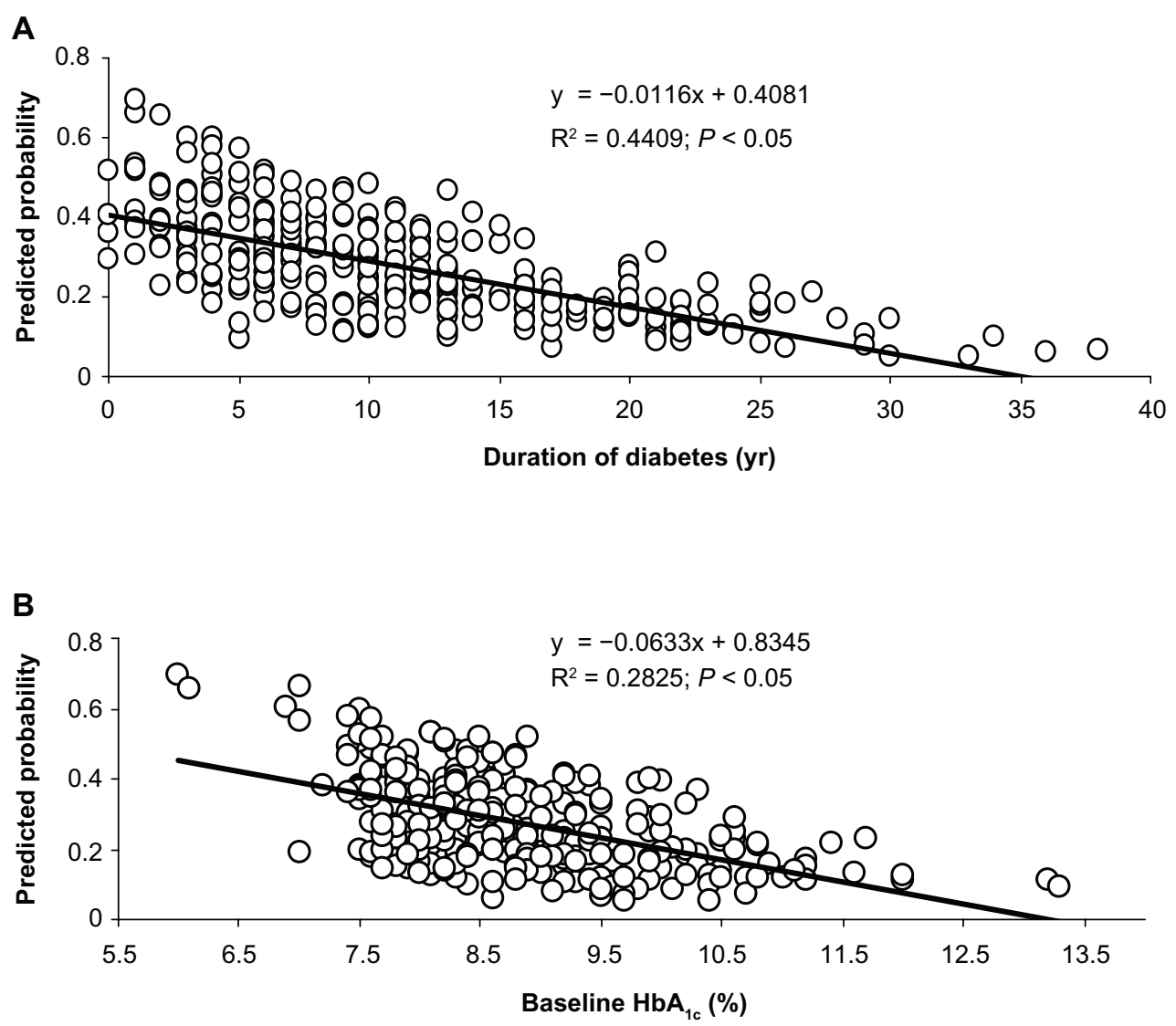

Figure 2 Relation linking diabetes duration and $\mathrm{HbA}_{\mathrm{Ic}}$ levels with predicted probability of target I-year metabolic response (HbA $\left.\leq 7 \%\right)$ after taking into account age, sex, BMI, and background therapy (metformin, sulphonylureas, or their combination). Diabetes duration (A) and baseline $\mathrm{HbA}_{\mathrm{lc}}$ levels (B) with predicted probability of target I-year metabolic response.

Abbreviations: $\mathrm{HbA}_{1 \mathrm{c}}$, hemoglobin $\mathrm{A}_{1 \mathrm{c}}$; $\mathrm{BMI}$, body mass index.

to note that in Pencek et al's ${ }^{28}$ analysis, the final weight loss observed in patients was significantly higher in females than in males, which is in agreement with our data.

Why glycemic response was better in men is not clear from our data; one possible explanation could be that women had a much longer duration of diabetes and were more frequently on therapy with metformin + sulphonylureas, suggesting a more preserved baseline $\beta$-cell function among men, which is also indirectly suggested by their higher HOMA-B median value. This hypothesis is validated by two findings: the first is the prediction that there is a negative effect on achievement of the glycemic target exerted by background baseline combination therapy; and the second is the positive relation linking basal HOMA-B and 1-year metabolic response, both of which were observed uniquely among females.

In agreement with previous experiences, weight loss after 1-year of exenatide therapy was about $5 \mathrm{~kg}$, on average, in both sexes; ${ }^{18,20}$ however, females achieved weight loss targets more frequently than males after 8 months and 12 months of exenatide therapy. The reason for this divergent response between genders - which was interestingly also reported in

Table 3 Predictors of weight loss targets in the overall population, as well as in males and females

\begin{tabular}{|c|c|c|c|}
\hline & $\begin{array}{l}\text { Males } \\
\text { OR }(95 \% \mathrm{Cl})\end{array}$ & $\begin{array}{l}\text { Females } \\
\text { OR }(95 \% \mathrm{Cl})\end{array}$ & $\begin{array}{l}\text { Overall } \\
\text { OR }(95 \% \mathrm{Cl})\end{array}$ \\
\hline Diabetes duration & $1.069(1.011-1.167)^{\mathrm{a}}$ & I.022 (0.975-I.07I) & $1.044(1.005-1.085)^{\mathrm{a}}$ \\
\hline Baseline BMI & $1.069(0.988-1.157)$ & $0.986(0.934-\mid .04 I)$ & $1.020(0.977-1.065)$ \\
\hline Baseline $\mathrm{HbA}_{\mathrm{Ic}}$ & $0.970(0.673-1.398)$ & $0.667(0.458-0.97 \mathrm{I})^{\mathrm{a}}$ & $0.809(0.627-1.044)$ \\
\hline Therapy* & $0.735(0.28 I-1.921)$ & $0.656(0.32 I-I .34 I)$ & $0.758(0.437-1.314)$ \\
\hline
\end{tabular}

Notes: Results are expressed as the I-year percent loss value from the baseline weight $\geq 75$ th percentile ( $\geq 8.5 \%$ ). In addition, the results are also expressed as $\mathrm{OR}$ ( $95 \% \mathrm{Cl}$ ) after a logistics regression model where the dependent variable was target outcome " $y$ " (yes = I; no = 0); age, duration of diabetes, baseline $\mathrm{Hb} \mathrm{I}_{\mathrm{Ic}}$, background antidiabetic therapy, and baseline BMI were the independent variables. *Therapy was categorized as metformin $=0$; sulphonylureas or associations $=\mathrm{I}$. ${ }^{\mathrm{a}}$ statistically significant. Abbreviations: $\mathrm{OR}$, odds ratio; $\mathrm{Cl}$, confidence interval; $\mathrm{BMI}$, body mass index; $\mathrm{HbA}_{\mathrm{Ic}}$, hemoglobin $\mathrm{A}_{\mathrm{Ic}}$. 
Table 4 Side effects and reasons for drop-outs at I year

\begin{tabular}{lll}
\hline & Males (n) & Females (n) \\
\hline Failure of therapy & 11 & 13 \\
Transfer to other therapy & 6 & 8 \\
Nausea & 60 & 63 \\
Vomiting & 13 & 14 \\
Diarrhea & 16 & 18 \\
Lack of compliance & 1 & 2 \\
Other & 1 & 5 \\
\hline
\end{tabular}

Abbreviation: $\mathrm{n}$, number.

a previous "real world" study, ${ }^{20}$ as well as in Pencek et al's ${ }^{28}$ meta-analysis - is not clear. The slightly higher mean BMI observed in women, even if nonsignificant, may have contributed to a greater weight loss after exenatide.

Additional results of this study were the relationship between the duration of diabetes and weight loss, which was significant only in men, as well as and the inverse association between higher basal $\mathrm{HbA}_{1 \mathrm{c}}$ levels and the achievement of significant weight loss only in women. This latter finding among the females in our study was confirmed by the evidence that there was a lower mean baseline $\mathrm{HbA}_{1 \mathrm{c}}$ concentration in "responders" compared to "non-responders" (8.49\% $\pm 0.88 \%$ versus $8.88 \% \pm 1.06 \% ; P=0.02$ ). Since previous studies reported that weight is an important risk factor for diabetes in women, ${ }^{29}$ the idea that plasma glucose is selectively related to body weight in obese women, ${ }^{30}$ and that women are more obese than men at the time of diagnosis of diabetes, ${ }^{31}$ it is possible to speculate that all these gender-specific "traits" may suggest that females carry an overall greater sensitivity to losing weight after exenatide treatment, especially in the presence of poor baseline metabolic control. Why there was a significant link between longer duration of diabetes and significant weight loss in males, as well as in the overall population, is unknown.

The prevalence of adverse reactions and drop-outs was quite similar between genders, which was in agreement with previously published trials. ${ }^{28}$ No relation was found between weight loss and gastrointestinal side effects in both males and females.

This study has an evident main limitation since patients were chosen with a "post hoc" design; but, nevertheless, we believe that the study holds the advantage of being a "real world" experience. To our knowledge, there are few studies that have been performed in clinical settings that have been especially aimed at investigating gender difference with regards to therapy with GLP-1 receptor agonists.

\section{Conclusion}

In summary, this study confirms that therapy with exenatide is efficacious in improving metabolic control, which is associated with a significant weight loss in patients with type 2 diabetes, irrespective of sex. Some baseline variables predict 1-year outcomes; specifically, lower baseline $\mathrm{HbA}_{1 \mathrm{c}}$ values and a shorter duration of disease predict a better glycemic response in the overall population. Therefore, the first conclusion that can be drawn from our results is that therapy with exenatide should be initiated not too late, seemingly before patients present with treatment failure while on oral therapy. Interestingly, the duration of disease acts biphasically - a higher duration of diabetes was associated with a worse glycemic response, while exactly the opposite was observed for a reduction in body weight.

A second aspect coming from the data of the present study is that males seem to have a more efficacious response after exenatide therapy, probably due to their reduced duration of disease as well as to a less exhausted $\beta$-cell mass at baseline, as indirectly suggested by the lower rate of males on combination therapy. In addition, gender seems to have a different impact on weight-lowering effects exerted by exenatide, with women being seemingly more sensitive than men.

The findings of this study support the hypothesis that dissimilar baseline diabetes-related characteristics between genders are mostly responsible for the different therapeutic outcomes after exenatide therapy. However, due to the observational retrospective feature of this study, all suggested gender differences need further confirmation by trials specifically designed to assess these factors.

\section{Acknowledgments}

The authors acknowledge the following additional collaborators from the Exenatide Study Group of Tuscany: (1) Massa: Dolci M, Gregori G, Mori M; (2) Lucca: Casadidio I, Cuccuru I; (3) Versilia: Valicenti A, Bertoli S; (4) Livorno: Di Cianni G, Turco A; (5) Pisa: Piaggi P (statistician).

This paper in abstract form has been partially presented as a poster at the 72nd scientific sessions of the American Diabetes Association, Philadelphia, PA, USA, June 8-12, 2012.

This work was supported by a grant of the Fondazione Cassa di Risparmio di Pistoia e Pescia, Pistoia, Italy.

All authors participated in the study design and data collection. GS was primarily responsible for the data analysis; all other authors were responsible for writing up the results, as well as for discussing and editing the manuscript.

\section{Disclosure}

The authors report no conflicts of interest in this work. 


\section{References}

1. Turner R, Cull C, Holman R. United Kingdom Prospective Diabetes Study 17: a 9-year update of a randomized, controlled trial on the effect of improved metabolic control on complications in non-insulin-dependent diabetes mellitus. Ann Intern Med. 1996;124(1 Pt 2):136-145.

2. Stettler C, Allemann S, Jüni P, et al. Glycemic control and macrovascular disease in types 1 and 2 diabetes mellitus: Meta-analysis of randomized trials. Am Heart J. 2006;152(1):27-38.

3. Alvarez Guisasola F, Tofé Povedano S, Krishnarajah G, Lyu R, Mavros P, Yin D. Hypoglycaemic symptoms, treatment satisfaction, adherence and their associations with glycaemic goal in patients with type 2 diabetes mellitus: findings from the Real-Life Effectiveness and Care Patterns of Diabetes Management (RECAP-DM) Study. Diabetes Obes Metab. 2008;10 Suppl 1:25-32.

4. Weber KK, Lohmann T, Busch K, Donati-Hirsch I, Riel R. High frequency of unrecognized hypoglycaemias in patients with type 2 diabetes is discovered by continuous glucose monitoring. Exp Clin Endocrinol Diabetes. 2007;115(8):491-494.

5. Inzucchi SE, Bergenstal RM, Buse JB, et al; for American Diabetes Association (ADA), European Association for the Study of Diabetes (EASD). Management of hyperglycemia in type 2 diabetes: a patientcentered approach: position statement of the American Diabetes Association (ADA) and the European Association for the Study of Diabetes (EASD). Diabetes Care. 2012;35(6):1364-1379.

6. Ahrén B. GLP-1-based therapy of type 2 diabetes: GLP-1 mimetics and DPP-IV inhibitors. Curr Diab Rep. 2007;7(5):340-347.

7. Mikhail N. Incretin mimetics and dipeptidyl peptidase 4 inhibitors in clinical trials for the treatment of type 2 diabetes. Expert Opin Investig Drugs. 2008;17(6):845-853.

8. Scott LJ. Exenatide extended-release: a review of its use in type 2 diabetes mellitus. Drugs. 2012;72(12):1679-1707.

9. Farilla L, Bulotta A, Hirshberg B, et al. Glucagon-like peptide 1 inhibits cell apoptosis and improves glucose responsiveness of freshly isolated human islets. Endocrinology. 2003;144(12):5149-5158.

10. Li YZ, Hansotia T, Yusta B, Ris F, Halban PA, Drucker DJ. Glucagon-like peptide-1 receptor signaling modulates beta cell apoptosis. J Biol Chem. 2003;278(1):471-478.

11. Flint A, Raben A, Astrup A, Holst JJ. Glucagon-like peptide 1 promotes satiety and suppresses energy intake in humans. J Clin Invest. 1998; 101(3):515-520.

12. Baggio LL, Huang Q, Brown TJ, Drucker DJ. A recombinant human glucagon-like peptide (GLP)-1-albumin protein (albugon) mimics peptidergic activation of GLP-1 receptor-dependent pathways coupled with satiety, gastrointestinal motility, and glucose homeostasis. Diabetes. 2004;53(9):2492-2500.

13. Nauck MA, Kleine N, Orskov C, Holst JJ, Willms B, Creutzfeldt W. Normalization of fasting hyperglycaemia by exogenous glucagon-like peptide 1 (7-36 amide) in type 2 (non-insulin-dependent) diabetic patients. Diabetologia. 1993;36(8):741-744.

14. Amori RE, Lau J, Pittas AG. Efficacy and safety of incretin therapy in type 2 diabetes: systematic review and meta-analysis. JAMA. 2007;298(2):194-206.

15. Barnett AH. New treatments in type 2 diabetes: a focus on the incretin-based therapies. Clin Endocrinol (Oxf). 2009;70(3):343-353.
16. Monami M, Marchionni N, Mannucci E. Glucagon-like peptide-1 receptor agonists in type 2 diabetes: a meta-analysis of randomized clinical trials. Eur J Endocrinol. 2009;160(6):909-917.

17. Norris SL, Lee N, Thakurta S, Chan BK. Exenatide efficacy and safety: a systematic review. Diabet Med. 2009;26(9):837-846.

18. Shyangdan DS, Royle PL, Clar C, Sharma P, Waugh NR. Glucagon-like peptide analogues for type 2 diabetes mellitus: systematic review and meta-analysis. BMC Endocr Disord. 2010;10:20.

19. NHS National Institute for Health and Clinical Excellence. Clinical guidelines CG87: Type 2 diabetes - newer agents (partial CG66) (CG87) [homepage on the Internet]. London, UK: NHS National Institute for Health and Clinical Excellence; 2009. Available from: http://www.nice. org.uk/cg87. Accessed March 25, 2013.

20. Buysschaert M, Preumont V, Oriot PR, et al. One-year metabolic outcomes in patients with type 2 diabetes treated with exenatide in routine practice. Diabetes Metab. 2010;36(5):381-388.

21. Bergenstal RM, Garrison LP Jr, Miller LA, et al. Exenatide BID Observational Study (ExOS): results for primary and secondary endpoints of a prospective research study to evaluate the clinical effectiveness of exenatide BID use in patients with type 2 diabetes in a real-world setting. Curr Med Res Opin. 2011;27(12):2335-2342.

22. Adam TC, Westerterp-Plantenga MS. Nutrient-stimulated GLP-1 release in normal-weight men and women. Horm Metab Res. 2005; 37(2):111-117.

23. Wallace TM, Levy JC, Matthews DR. Use and abuse of HOMA modeling. Diabetes Care. 2004;27(6):1487-1495.

24. Intensive blood-glucose control with sulphonylureas or insulin compared with conventional treatment and risk of complications in patients with type 2 diabetes (UKPDS 33). UK Prospective Diabetes Study (UKPDS) Group. Lancet. 1998;352(9131):837-853.

25. Effect of intensive blood-glucose control with metformin on complications in overweight patients with type 2 diabetes (UKPDS 34). UK Prospective Diabetes Study (UKPDS) Group. Lancet. 1998;352(9131):854-865.

26. Marchetti P, Dotta F, Lauro D, Purrello F. An overview of pancreatic beta-cell defects in human type 2 diabetes: implications for treatment. Regul Pept. 2008;146(1-3):4-11.

27. Charpentier G, Vaur L, Halimi S, et al; for DIAMETRE. Predictors of response to glimepiride in patients with type 2 diabetes mellitus. Diabetes Metab. 2001;27(5 Pt 1):563-571.

28. Pencek R, Blickensderfer A, Li Y, Brunell SC, Anderson PW. Exenatide twice daily: analysis of effectiveness and safety data stratified by age, sex, race, duration of diabetes, and body mass index. Postgrad Med. 2012;124(4):21-32.

29. Colditz GA, Willett WC, Stampfer MJ, et al. Weight as a risk factor for clinical diabetes in women. Am J Epidemiol. 1990;132(3):501-513.

30. Seghieri G, Tesi F, Anichini R, et al. Gender modulates the relationship between body weight and plasma glucose in overweight or obese subjects. Diabetes Res Clin Pract. 2008;80(1):134-138.

31. Wannamethee SG, Papacosta O, Lawlor DA, et al. Do women exhibit greater differences in established and novel risk factors between diabetes and non-diabetes than men? The British Regional Heart Study and British Women's Heart Health Study. Diabetologia. 2012;55(1):80-87.

Diabetes, Metabolic Syndrome and Obesity: Targets and Therapy

\section{Publish your work in this journal}

Diabetes, Metabolic Syndrome and Obesity: Targets and Therapy is an international, peer-reviewed open-access journal committed to the rapid publication of the latest laboratory and clinical findings in the fields of diabetes, metabolic syndrome and obesity research. Original research, review, case reports, hypothesis formation, expert
Dovepress

opinion and commentaries are all considered for publication. The manuscript management system is completely online and includes a very quick and fair peer-review system, which is all easy to use. Visit $\mathrm{http}: / /$ www.dovepress.com/testimonials.php to read real quotes from published authors. 